\title{
Price stickers do not alter drug usage
}

Jan C. Horrow MD, Henry Rosenberg MD

Anaesthetists choose daily among wide varieties of neuromuscular blocking drugs and rapidly acting hypnotic agents. This study sought to determine whether definitive, immediate knowledge of drug cast might influence clinician choices, ultimately reducing the cost of anaesthesia care. Faculty anaesthetists, residents in training, and nurse anaesthetists served as subjects in this prospective, sequential, blinded study of prescribing habits. Weekly inventories of selected neuromuscular blocking and rapidly acting hypnotic agents were performed over $24 \mathrm{wk}$ at a tertiary-care hospital. Supermarket style price stickers plainly indicating the hospital cost of each unit of drug appeared continually for 13 wk following an initial 11 wk control period. Both actual usage data in priced units as well as data normalized by total anaesthesia duration underwent comparison between control and priced periods. The usage of pancuronium, vecuronium, atracurium, mivacurium, succinylcholine, thiopentone, etomidate, and propofol did not differ in the control from the priced periods. Pipecuronium decreased after sticker placement ( 2 vs 1 vials $w k^{-1}$ median, $P<0.05$ ), as did methohexitone ( $39 \pm 9.0[S D]$ vs $29 \pm 11$ syringes $\cdot w k^{-1}, P<0.05$ ). Ketamine usage normalized by total anaesthesia duration increased $(P<0.05)$ following sticker placement. The weekly cost of all drugs inventoried normalized for caseload did not differ during the measurement periods. Immediate cost awareness, implemented simply as price stickers on drug units, had minimal impact on clinicians' drug usage in a tertiary care setting.

\section{Key words}

ANAESTHESIA: costs;

HYPNOTICS: etomidate, ketamine, methohexital, propofol, thiopentone;

NEUROMUSCULAR BLOCKING DRUGS: atracurium, doxacurium, mivacurium, pancuronium, pipecuronium, succinylcholine, vecuronium.

From the Department of Anesthesiology, Hahnemann University, Philadelphia, PA.

Supported by the Hahnemann Anesthesia Research Foundation.

Address correspondence to: Dr. Horrow at Broad \& Vine,

Philadelphia, PA 19102-1192, USA.

Accepted for publication 9 th April, 1994
Les anesthésistes ont le choix entre plusieurs myorelaxants et agents hypnotiques à début d'action rapide. Cette étude vise à déterminer si la connaissance immédiate du coût de ces produits influence ce choix et ultimement diminue le coût de l'anesthésie. Des anesthésistes, résidents en formation et infirmièresanesthésistes participent à cette étude prospective, séquentielle et à l'aveugle des attitudes vis-à-vis l'utilisation de ces produtts. Des inventaires hebdomadaires des myorelaxants et hypnotiques à début d'action rapide choisis sont réalisés sur une période de 24 semaines dans un hôpital spécialisé en soins tertiaires. Des autocollants de type commercial indiquant clairement le coût de chacun des produits apparaissent pendant 13 semaines à la suite d'une période de contrôle initiale de onze semaines. Les données en unités de prix et les données normalisées pour la durée totale de l'anesthésie sont toutes les deux comparées pendant les périodes de contrôle et d'affichage du prix. Liutilisation du pancuronium, du vécuronium, de l'atracurium, du mivacurium, de la succinylcholine, du thiopentone, de l'étomidate et du propofol est la même pendant la période de contrôle et la période d'affichage. L'utilisation du pipécuronium diminue après la mise en place de l'autocollant (médiane, 2 vs 1 vials $\left.\cdot \mathrm{sem}^{-1}, P<0,05\right)$ ainsi que le méthohéxitone (39 $\pm 9,0[S D]$ vs $29 \pm 11$ seringues $\cdot \operatorname{sem}^{-1}, P<0,05$ ). Lutilisation de la kétamine normalisée avec la durée totale d'anesthésie diminue $(P<0,05)$ après l'affichage. Le coût hebdomadaire de tous les produits inventoriés normalisé avec le charge clinique est le même pour les deux périodes de mesure. L'affichage du coût au moyen d'autocollants influence très peu le choix des produits par les cliniciens dans le cadre d'un hôpital spécialisé en soins tertiaires.

Cost containment in medicine receives much attention in the popular media, but little study from within the various medical disciplines. Expenditures for anaesthesia drugs in Canada account for over one-third of the nonprofessional costs of anaesthesia care, and about $10 \%$ of a hospital's anaesthesia drug budget. ' A physician's choice of agent given therapeutically equivalent pharmaceuticals may depend on numerous factors, including previous experience; information obtained from continuing medical education endeavors, peer-reviewed literature, advertisements, and pharmaceutical industry representatives; patient factors, including anticipated complications; convenience and expediency; and cost.

While many of these factors are readily available to 
the physician, cost data are not. Ignorance of the cost of products may result in a physician choosing the more expensive of otherwise equivalent products. More so, the perceived benefits of a drug with less chance of a given side effect may deflate considerably when the excessive cost of that drug becomes known: e.g., it may be worth an additional US $\$ 20$ to decrease the possibility of tachycardia from neuromuscular blockade for selected patients, but not for every patient.

Perhaps more so than any other group of physicians, anaesthetists attain an intense familiarity with their prescribed pharmaceuticals owing to the drugs' immediate actions and to the intense observation and monitoring accompanying drug administration. Furthermore, selection of a particular agent from among many involves for most anaesthetists an actual physical process, such as holding the vial or syringe, rather than merely writing the drug's name on a prescription pad. For these reasons, anaesthetists form an appropriate group in whom to investigate cost containment behaviour.

Simply placing price stickers on drug packages would provide a highly visible, first step in cost awareness. To initiate investigation of how cost awareness impacts upon drug usage, this study explored whether the simple manoeuvre of cost sticker placement would change drug usage. No detailed exploration of the behavioural aspects of physician prescribing habits was attempted.

\section{Methods}

Following approval by the institutional review board, anaesthetists at our tertiary care institution unknowingly participated in a 24-wk investigation. Initial data collection documented drug usage without cost information (control period), following which drug usage with cost information (price period) was measured.

On every Sunday afternoon from 17 January 1993 until 4 July 1993, pharmacists audited the weekly utilization of selected neuromuscular relaxant and sedativehypnotic agents by an inventory of drug stockroom quantities. Table I lists the pharmaceutical agents studied. Exclusion of controlled substances permitted minimal disclosure of the conduct of the study to clinical personnel. Drug units removed from storage but not administered to patients for whatever reason (e.g., broken vials, wasted drug) counted as units administered to patients: units removed from storage but returned there in the same week counted as if never removed. Stockroom inventory determined actual drug usage, as opposed to a review of anaesthesia records or patient charge records, which would not necessarily include drugs prepared but wasted. All drugs were immediately and equally available for use, i.e., stocked at the anaesthetizing locations.

On 4 April 1993, following 11 wk of data collection
TABLE I Drugs studied

\begin{tabular}{llc}
\hline Name & Unit supplied & Cost per unit \\
\hline Neuromuscular relaxants & \\
Pancuronium & $10 \mathrm{mg}$ in $5 \mathrm{ml}$ vial & US\$ 1.26 \\
Vecuronium & $10 \mathrm{mg}$ powder & $\$ 17.59$ \\
Pipecuronium & $10 \mathrm{mg}$ powder & $\$ 33.51$ \\
Atracurium & $100 \mathrm{mg}$ in $10 \mathrm{ml}$ & $\$ 38.34$ \\
Doxacurium & $5 \mathrm{mg}$ in $5 \mathrm{ml}$ & $\$ 27.92$ \\
Mivacurium & $20 \mathrm{mg}$ in $10 \mathrm{ml}$ & $\$ 12.69$ \\
Succinylcholine & $100 \mathrm{mg}$ in $5 \mathrm{ml}$ syringe & $\$ 0.20$ \\
& & \\
Sedative-hypnotics & & \\
Thiopentone & $500 \mathrm{mg}$ in $20 \mathrm{ml}$ syringe & US\$ $\$ 0.85$ \\
Methohexitone & $200 \mathrm{mg}$ in $20 \mathrm{ml}$ syringe & $\$ 2.33$ \\
Etomidate & $4 \mathrm{mg}$ in $20 \mathrm{ml}$ & $\$ 19.32$ \\
Ketamine & $500 \mathrm{mg}$ in $5 \mathrm{or} 10 \mathrm{ml}$ vials & $\$ 11.75$ \\
Propofol vials & $500 \mathrm{mg}$ in $50 \mathrm{ml}$ & $\$ 22.84$ \\
Propofol ampoules & $200 \mathrm{mg}$ in $20 \mathrm{ml}$ & $\$ 9.14$ \\
\hline
\end{tabular}

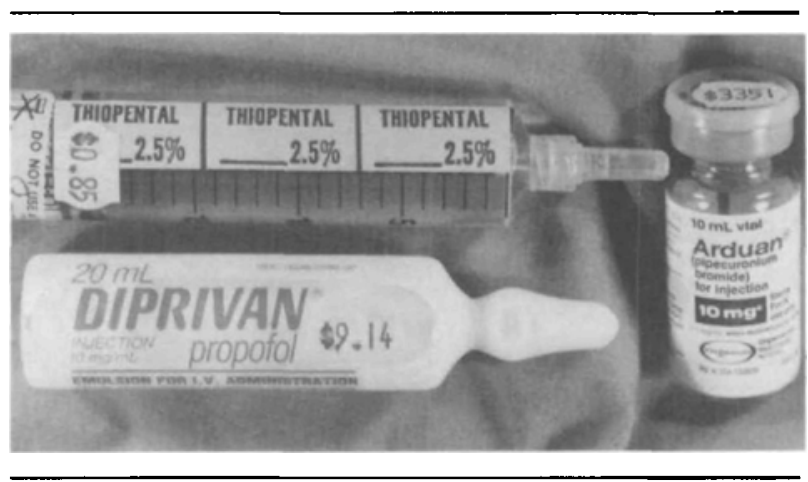

FIGURE Examples of price sticker placement. In each case, sticker placement required visuatization of the unit price for selection of the drug from its storage place. See text for further details.

without immediately available cost information, the investigators placed supermarket price stickers ${ }^{*}$ on all available units of the selected pharmaceuticals in the suite of 13 operating rooms. This included all units in the storage area, in mobile carts used to stock operating rooms, and in drug drawers in each operating room. The price listed on the sticker equalled the cost to the hospital for that drug unit (Table I). Each sticker contained a dollar sign followed by the cost in dollars and cents so that its meaning as a price was unmistakable. Placement of each sticker assured easy visibility when viewing the unit on the shelf of the storage area or in the drawer of the anaesthesia cart in each operating room (Figure). No unit could be selected and committed to use without the user seeing the price sticker. The investigators rejected the options of providing price information as "per milligram" or "per average dose" since highly variable wastage per

*Generously provided by Penn-Jersey Paper Co., Philadelphia, PA. 
unit makes that information inaccurate for cost assessment. For three medications, thiopentone, methohexitone, and succinylcholine, pharmacists prepared dated and labelled syringes containing the respective medications. Clinicians selected these prepared syringes from bins containing them in a refrigerated section of the storage area. For these agents, the investigators affixed to each syringe the cost of the drug contained in that syringe, not the total cost of the original unit of drug. At each weekly inventory after 4 April 1993, the pharmacists affixed cost stickers to all drug units placed in the storage area for clinical use.

The particular facility studied comprised 13 operating rooms in a private, urban, not-for-profit tertiary healthcare institution. The subject healthcare workers included 20 faculty anaesthetists, 32 anaesthesia residents at various training levels, and four nurse anaesthetists. No personnel joined or left the faculty during the study periods. There were no re-assignments of personnel during the 24-wk study period to subspecialty areas which might affect drug utilization. No data regarding drug prescribing habits of individual clinicians could occur or were desirable using the methods described above. These personnel provide approximately 12,000 anaesthetics per year, of which approximately 7,000 are performed in the suite of 13 operating rooms studied. Regional anaesthesia or monitored anaesthesia care comprise about $30 \%$ of these 7,000 anaesthetics. The surgical programme emphasizes cardiothoracic and orthopaedic disciplines, and includes an active trauma centre.

In the preceding eight years, occasional drug cost information had been provided to clinicians on a handful of sporadic occasions in the form of intermittent memoranda. No up-to-date summarized cost information appeared in the drug stockroom or in the operating rooms. Only two faculty anaesthetists (the authors, who had the least clinical exposure among the 20 faculty involved) and the two pharmacists knew about the weekly inventory activity and the purpose of the cost stickers. These faculty and pharmacists agreed in advance to respond to any inquiry regarding the origin of the cost stickers with a standard statement, "I don't know where they came from."

To adjust for seasonal variation in case load during the data collection period, the operating room data centre provided information weekly on the number of general anaesthetics administered in the 13-room operating suite studied as well as the total anaesthesia time for those cases administered general anaesthesia. This allowed normalization of drug usage data by number of cases or by total duration of cases in the event that the weekly caseload during the first control period of data collection differed from that during the second period.
The initial design called for two 11-wk measurement periods, the 11 replicates of weekly data providing a measure of the variability of the measurement process without which statistical comparison could not occur. Estimates of data variability determined that 11 replicates would provide $90 \%$ statistical power to detect a difference resulting in an estimated $10 \%$ overall cost saving. During the second 11-wk period, an internal inconsistency caused discarding of two weeks' of data for a specific drug (see results for details). For this reason, the second period was extended to $13 \mathrm{wk}$. Statistical tests utilized data for all $24 \mathrm{wk}$, unless otherwise discarded.

The number of units of each drug utilized in the week just passed equalled its inventory count on Sunday minus its inventory count the previous Sunday plus the number of units added to inventory during the week. Within each grouping (control and priced) these data underwent Lillefors' test for normal distribution. Comparison of normally distributed data, reported as mean $\pm \mathrm{SD}$, proceeded with the unpaired two-tailed Student's $t$ test, while the Mann-Whitney U test compared those not distributed normally. The Mann-Whitney $U$ test compared all data normalized by number of general anaesthetics or by total duration of general anaesthetics. For all comparisons, $P$ $<0.05$ determined significance.

\section{Results}

Tables II and III display the weekly drug usage data and caseload information. Low usage of doxacurium (three vials total in the control period followed by none in the price period) rendered statistical comparisons unreliable. The initial 11-wk control period did not differ from the subsequent 13-wk priced period in terms of the number of general anaesthetics administered per week (97 \pm 8 vs $94 \pm 10$ ). However, the total durations of those anaesthetics differed: $23037 \pm 1873$ vs $21283 \pm$ $1912 \mathrm{~min}$ per week, $P=0.034$ ), reflecting perhaps more efficient surgery with progression of the academic year.

On two sequential Sundays, the inventory produced unusual pipecuronium counts. On 13 June 1993, the pipecuronium count abruptly decreased to seven from 13 vials the previous Sunday, only to return to 13 vials the following week. With zero net usage for the two-week period, the investigators assume each week's usage must also be zero, irrespective of this transient sequestration of vials from the storeroom area. On two other occasions, sudden increases in the atracurium inventory count $(24$ to 38 vials one week and 4 to 14 vials several weeks later) disclosed recording errors in added inventory. These instances, representing return to the storeroom area of unused vials sequestered in anaesthetizing locations, rendered data for those weeks unreliable. Those data did not participate in the analysis. Tables II and III present 
TABLE II Results of weekly inventory of neuromuscular blocking drugs

\begin{tabular}{|c|c|c|c|c|}
\hline & Summary statistic & Control period & Sticker period & $P$ \\
\hline \multicolumn{2}{|l|}{ \#G/As per week } & $97 \pm 8$ & $94 \pm 10$ & 0.56 \\
\hline \multicolumn{2}{|c|}{ Total anaesthesia duration $\cdot \mathrm{wk}^{-1}(\mathrm{~min})$} & $23037 \pm 1873$ & $21284 \pm 1912$ & 0.03 \\
\hline \multirow[t]{2}{*}{ Pancuronium } & $\#$ Units, mean \pm SD & $71 \pm 14$ & $66 \pm 29$ & 0.60 \\
\hline & $\#$ units $\cdot 1000$ min $^{-1 *}$ & 2.91 median & 3.22 median & 0.66 \\
\hline \multirow[t]{2}{*}{ Vecuronium } & \# Units, mean \pm SD & $84 \pm 17$ & $79 \pm 34$ & 0.67 \\
\hline & $\#$ units $1000 \mathrm{~min}^{-1 *}$ & 3.70 median & 3.61 median & 0.98 \\
\hline \multirow[t]{2}{*}{ Pipecuronium } & \#Units, median & 2 [IQR 1-7] & 1 [IQR 0-1] & 0.03 \\
\hline & $\#$ units $\cdot 1000 \mathrm{~min}^{-1 *}$ & 0.08 median & 0.04 median & 0.04 \\
\hline \multirow[t]{2}{*}{ Atracurium } & \# Units, mean \pm SD & $19 \pm 10$ & $14 \pm 7$ & 0.26 \\
\hline & $\#$ units $1000 \mathrm{~min}^{-1 *}$ & 0.62 median & 0.58 median & 0.17 \\
\hline \multirow[t]{2}{*}{ Mivacurium } & \# Units, median & 1 [IQR 0-1] & 0.5 [IQR 0-2] & 0.81 \\
\hline & $\#$ units $\cdot 1000 \mathrm{~min}^{-1 *}$ & 0.04 median & 0.05 median & 0.78 \\
\hline \multirow[t]{2}{*}{ Succinylcholine } & $\#$ Units, mean $\pm S D$ & $93 \pm 15$ & $80 \pm 27$ & 0.16 \\
\hline & $\#$ units $1000 \mathrm{~min}^{-1 *}$ & 4.40 median & 4.07 median & 0.58 \\
\hline
\end{tabular}

Entries are mean $\pm S D$ unless otherwise specified.

Abbreviations: IQR, interquartile range; G/A, general anaesthetic.

* Number of units (vials, ampoules, or syringes as applicable) used per week normalized by the total duration of general anaesthetics that week, expressed as units per $1000 \mathrm{~min}$ of anaesthesia.

TABLE III Results of weekly inventory of sedative-hypnotic drugs

\begin{tabular}{|c|c|c|c|c|}
\hline & Summary statistics & Control period & Sticker period & $P$ \\
\hline \multicolumn{2}{|l|}{ \#G/As per week } & $97 \pm 8$ & $94 \pm 10$ & 0.56 \\
\hline \multicolumn{2}{|c|}{ Total anaesthesia duration $\cdot \mathrm{wk}^{-1}(\mathrm{~min})$} & $23037 \pm 1873$ & $21284 \pm 1912$ & 0.03 \\
\hline \multirow[t]{2}{*}{ Thiopentone } & \# Units, mean \pm SD & $169 \pm 24$ & $159 \pm 23$ & 0.30 \\
\hline & $\#$ units $\cdot 1000 \mathrm{~min}^{-1 *}$ & 7.43 median & 7.03 median & 0.71 \\
\hline \multirow[t]{2}{*}{ Methohexitone } & $\#$ Units, mean $\pm S D$ & $39 \pm 9.0$ & $29 \pm 11$ & 0.02 \\
\hline & $\#$ units $\cdot 1000 \mathrm{~min}^{-1 *}$ & 1.70 median & 1.28 median & 0.14 \\
\hline \multirow{2}{*}{ Etomidate } & $\#$ Units, mean \pm SD & $17 \pm 9.3$ & $11 \pm 4.5$ & 0.08 \\
\hline & $\#$ units $\cdot 1000 \mathrm{~min}^{-1 *}$ & 0.65 median & 0.59 median & 0.24 \\
\hline \multirow[t]{2}{*}{ Ketamine } & \# Units, median & 1 [IQR 1-2] & 3 [IQR $1-4]$ & 0.06 \\
\hline & $\#$ units $\cdot 1000 \mathrm{~min}^{-1 *}$ & 0.05 median & 0.15 median & 0.03 \\
\hline \multirow[t]{2}{*}{ Propofol amps } & \# Units, median & 1 [IQR a-1] & 0.5 [IQR 0-2] & 0.37 \\
\hline & $\#$ units $\cdot 1000 \mathrm{~min}^{-1 *}$ & 2.46 median & 2.56 median & 0.66 \\
\hline \multirow[t]{2}{*}{ Propofol vials } & $\#$ Units, mean $\pm S D$ & $11 \pm 3.6$ & $10 \pm 4.3$ & 0.64 \\
\hline & $\#$ units. $1000 \mathrm{~min}^{-1 *}$ & 0.49 median & 0.46 median & 0.98 \\
\hline
\end{tabular}

Entries are mean $\pm S D$ unless otherwise specified.

Abbreviations: IQR, interquartile range; G/A, general anaesthetic.

* Number of units (vials, ampoules, or syringes as applicable) used per week normalized by the total duration of general anaesthetics that week, expressed as units per $1000 \mathrm{~min}$ of anaesthesia.

the results of the analysis, presented first for neuromuscular blockers and then for sedative-hypnotics.

\section{Neuromuscular relaxants}

Pancuronium, vecuronium, and succinylcholine all enjoyed widespread usage during both control and priced periods. Pipecuronium and mivacurium usages did not distribute normally. Cost awareness did not affect usage of pancuronium, vecuronium, succinylcholine, mivacurium, or atracurium. In particular, cost awareness neither decreased usage of the costlier drugs vecuronium, mivacurium, and atracurium nor increased usage of the less expensive choices pancuronium and succinylcholine. Pipecuronium usage, however, did decrease following placement of price stickers on vials (median two vials per week, interquartile range one to seven during control period vs median one, interquartile range zero to one during priced period, $P=0.03$ ). This difference persisted following normalization of data for total anaesthesia time $(P=0.042)$.

At $\$ 38.34$ per multidose vial, the package of atracurium carried the highest price sticker. At the authors' institution, renal transplantation procedures almost exclusively employ atracurium, and last $6.25 \mathrm{hr}$ on average. 
TABLE IV Weekly cost of drugs inventoried

\begin{tabular}{|c|c|c|c|c|c|c|}
\hline & \multicolumn{2}{|l|}{ Relaxants } & \multicolumn{2}{|c|}{ Sedative-hypnotics } & \multicolumn{2}{|c|}{ All drugs inventoried } \\
\hline & Control & Sticker & Control & Sticker & Control & Sticker \\
\hline Cost (US\$) & $2423 \pm 514$ & $1949 \pm 642$ & $1414 \pm 322$ & $1221 \pm 267$ & $3837 \pm 700$ & $3179 \pm 723^{*}$ \\
\hline Cost per G/A & $25 \pm 6.5$ & $21 \pm 7.5$ & $14 \pm 3.5$ & $13 \pm 3.2$ & $40 \pm 8.8$ & $34 \pm 8.8$ \\
\hline Cost $\cdot 1000 \mathrm{hr}^{-1}$ & $106 \pm 25$ & $92 \pm 31$ & $62 \pm 14$ & $58 \pm 13$ & $168 \pm 34$ & $151 \pm 35$ \\
\hline
\end{tabular}

All entries are mean $\pm S D$ in US\$. G/A, general anaesthetic.

*Different from control, $P=0.038$.

Since atracurium use may reflect either the number or duration of renal transplantation procedures as well as cost awareness, a two-way analysis of variance attempted to identify either cost awareness treatment (control or priced period) or the number or duration of renal transplantation procedures per week as determinants of atracurium usage. None of these factors predicted atracurium usage.

\section{Sedative-hypnotics}

Not surprisingly, thiopentone proved the most frequently employed sedative-hypnotic among those studied in both the control and priced periods. Data for thiopentone, methohexitone, etomidate, and vials of propofol conformed to the normal distribution, but those for ketamine and ampoules of propofol did not. Usage of thiopentone, etomidate, and propofol (vials and ampoules alike) did not differ during the control and priced periods (see Table III). Methohexitone usage declined during the priced period (29 \pm 11 syringes per week vs $39 \pm 9$ during the control period, $P=0.021$ ). However, this difference did not remain when data were normalized by total anaesthesia duration $(P=0.139)$.

Data permitted no conclusions regarding changes in ketamine usage: one vial per week median (interquartile range one to two) during the control period vs three vials per week median (interquartile range one to four) during the price period $(P=0.059)$. Normalization by total anaesthesia duration demonstrated an increased usage of ketamine $(P=0.027)$ following price sticker placement.

Table IV presents the aggregate cost of drugs inventoried by class. Although the weekly cost of all drugs inventoried decreased by $17 \%$, this difference paralleled the decrease in total anaesthesia time during the price sticker period. When corrected for either number of cases or total anaesthesia duration, the cost of anaesthetic drug did not differ between the two periods.

\section{Discussion}

Cost containment in anaesthesia has previously focused mostly on monitoring expense, ${ }^{2-5}$ and the impact of gas delivery systems on cost. ${ }^{6}$ Neuromuscular blocking drug cost received particular scrutiny when newer, expensive formulations first became available. ${ }^{7,8}$ Similarly, questions regarding the cost-benefit ratio of opioid anaesthesia arose once that technique became popular. ${ }^{9}$

A cost analysis for various veterinary anaesthetics appeared a decade ago, indicating thiamylal to be less expensive than inhalational techniques. ${ }^{10}$ That investigation involved prospective, random assignment to various anaesthetic techniques of 149 dogs and cats for elective ovariohysterectomies. Bengston et al. compared anaesthetic costs retrospectively for cholecystectomy, concluding that a low-flow nitrous oxide-oxygen technique provided minimal cost. ${ }^{11}$

Petty quizzed anaesthesia residents regarding drug costs, supplies, and professional fees. Most respondents over-estimated drug costs. ${ }^{12}$ Petty claimed that cost awareness is needed for cost containment. ${ }^{12}$ While the necessity for cost awareness remains a truism, it has not been determined whether cost awareness proves sufficient to effect cost savings. Data from the current study demonstrate that cost awareness alone may be insufficient to extract marginal cost savings in certain settings.

The current study demonstrated no substantive effect of cost sticker placement on the usage of either neuromuscular blocking agents or of rapidly-acting sedativehypnotic agents. Although three of the inventoried agents demonstrated changes in usage, the altered patterns of use had little impact on costs.

Why might this study have failed to show an effect? Perhaps the investigators chose the study drugs poorly. In fact, these particular classes of compounds represent ideal agents for such study. The neuromuscular blockers and the rapidly-acting hypnotic agents each contain a large selection of individual agents with a wide range and distribution of costs. For each class of compound, there is no inexpensive, ideal agent. Frequent use of these agents for anaesthesia permits collection of sufficient data for valid usage comparisons.

Perhaps the design of this experiment prevented correct outcome variable measurement. Ideally, the design should be randomized and double-blinded. The current design, using an initial blinded 11-wk control period followed 
by a 13-wk priced period, is sequential and nonrandomized. Since price sticker placement potentially confers cost awareness for an indefinite time period, control and price periods could not be interlaced and the control period had to precede the priced period. A random design requires a renewable source of clinicians.

Perhaps the drug usage measurement technique contained flaws. Some data suggest an excessive weekly variation of use for some drugs inventoried, which would support the notion of measurement error in usage. In addition, Table IV indicates a trend toward lower cost per general anaesthetic or per $1000 \mathrm{hr}$ of anaesthesia in the sticker period, suggesting insufficient power to identify a real difference. However, the mean usage data for the two periods do not reveal any tendency from more expensive products to less expensive ones. For this reason, the authors believe that even if the weekly variations had been smaller or the data collection periods longer, no significant cost impact would be obtained.

Another reason why the study might have failed to show an effect is an unsuspected high awareness by clinicians of drug costs before and throughout the study. Administration of a pre-study and post-study questionnaire would have permitted measurement of that factor. However, the investigators rejected this course, as it would have unblinded the design. Perhaps clinicians resented a perceived effort by others to alter their decisions by placing stickers. If so, the authors and pharmacists received no comments indicating such.

Most likely, the patterns of clinician's choices had already been determined by previous training and experience and were based on patient or educational factors, thus rendering cost considerations moot. We speculate that without a monetary or other direct incentive to choose less expensive drugs, these other influences remain dominant. Had cost savings been returned to the department, prescribing habits might have altered more substantially.

The least expensive drug may not ultimately yield the least expensive care. For example, propofol may decrease overall costs by sharply reducing the duration of postanaesthesia care unit stay despite its up-front higher cost compared with other intravenous anaesthetics. ${ }^{13,14} \mathrm{Al}-$ though this study did not address the total cost of patient care, these more global considerations should factor into decisions regarding more circumscribed efforts at reducing costs.

The data do not support any value to a simple effort at cost awareness, implemented as placement of supermarket type price stickers on packaged pharmaceutical units, at least in a residency program, tertiary care setting. Other clinical settings (e.g., community hospitals, ambulatory care units) may yield different results and will require further study. Might occasional memoranda informing clinicians of drug costs suffice? Since cost containment represents a serious, complex problem, the failure of a simple measure such as price stickers to impact on cost serves to underscore the need for more substantial mechanisms to induce thrift.

\section{Acknowledgements}

The authors thank Ellen Rupp, RPh and, Lai Huynh RPh, who conducted weekly inventories, and Ellen Horrow, who assisted in initial cost sticker placement.

\section{References}

1 Hudson RJ, Friesen RM. Health care "reform" and the costs of anaesthesia (Editorial). Can J Anaesth 1993; 40: $1120-5$.

2 Sage $D$ Monitoring during anaesthesia. N Z Med J 1989; 102: 313.

3 Pearson KS, Gomez MN, Moyers JR, Carter JG, Tinker $J H$. A cost/benefit analysis of randomized invasive monitoring for patients undergoing cardiac surgery. Anesth Analg 1989; 69: 336-41.

4 Tuman KJ, Ivankovich AD. High-cost, high-tech medicine: are we getting our money's worth? J Clin Anesth 1993; 5: 168-77.

5 Philip JH, Raemer DB. Selecting the optimal anesthesia monitoring array. Medical Instrumentation 1985; 19: 122-6.

6 Aldrete JA, Hendricks PL. Costs in anesthesia: an international survey. Acta Anaesthesiol Belg 1986; 37: 179-86.

7 Cruz JC. Reducing the cost of using neuromuscular relaxants (Letter). Anesth Analg 1986; 65: 315-6.

8 Aldrete JA, Hendricks PL. Cost of muscle relaxant drugs (Letter). Anesth Analg 1985; 64: 943-4.

9 Aldrete JA. Narcotic anesthesia: do the benefits justify the cost? (Letter). Anesthesiology 1985; 63: 565-6.

10 Bednarski RM, Bednarski LS, Muir III WW. Cost comparison of anesthetic regimens in the dog and cat. JAVMA 1984; 185: 869-72.

11 Bengtson JP, Sonander H, Stenqvist $O$. Comparison of costs of different anaesthetic techniques. Acta Anaesthesiol Scand 1988; 32: 33-5.

12 Petty $C$. Cost awareness is needed for cost containment (Editorial). AANA Journal 1988; 56: 188-9.

13 Korttila K, Östman P, Faure E, et al. Randomized comparison of recovery after propofol-nitrous oxide versus thiopentone-isoflurane-nitrous oxide anaesthesia in patients undergoing ambulatory surgery. Acta Anaesthesiol Scand 1990; 34: 400-3.

14 Wetchler $B V$. Economic impact of anesthesia decision making: they pay the money, we make the choice. J Clin Anesth 1992; 4: 20S-24S. 